\title{
Erratum to: Surgical treatment for early osteoarthritis. Part I: cartilage repair procedures
}

\author{
A. H. Gomoll • G. Filardo • L. de Girolamo • \\ J. Espregueira-Mendes • M. Marcacci - W. G. Rodkey • \\ J. R. Steadman $\cdot$ S. Zaffagnini $\cdot$ E. Kon
}

Published online: 10 December 2011

(C) Springer-Verlag 2011

\section{Erratum to: Knee Surg Sports Traumatol Arthrose \\ DOI 10.1007/s00167-011-1780-x}

In the original publication of the article, one of the co-author's name (J. Espregueira-Mendes) was misspelt and another author's initial (J. R. Steadman) was swapped. The complete and correct author group is provided below.

A. H. Gomoll · G. Filardo · L. de Girolamo · J. EspregueiraMendes - M. Marcacci · W. G. Rodkey - J. R. Steadman · S. Zaffagnini · E. Kon.

The online version of the original article can be found under doi:10.1007/s00167-011-1780-x.

\footnotetext{
A. H. Gomoll ( $\square)$

Cartilage Repair Center, Department of Orthopedic Surgery,

Brigham and Women's Hospital, Boston, MA, USA

e-mail: agomoll@yahoo.com

G. Filardo · M. Marcacci - S. Zaffagnini - E. Kon

Biomechanics Laboratory, III Clinic,

Rizzoli Orthopaedic Institute, Bologna, Italy

L. de Girolamo

Orthopaedics Biotechnologies Lab,

IRCCS Istituto Ortopedico, Galeazzi, Milan, Italy

J. Espregueira-Mendes

Clínica Espregueira-Mendes, Porto, Portugal

W. G. Rodkey · J. R. Steadman

Steadman Philippon Research Institute, Vail, CO, USA
} 